\title{
Expressão de intensidades: uma leitura sobre o conceito de essência na Ética de Espinosa
}

\author{
Expression of intensities: a reading of the concept of essence in \\ Spinoza's Ethics
}

do $10.21680 / 1983-2109.2021 v 28 n 57$ ID22727

\author{
Fellipe Pinheiro de Oliveira \\ Centro Federal de Educação Tecnológica (CEFET-RJ) \\ 0000-0002-7245-4357 \\ fellipepinheirodeoliveira@gmail.com
}

\begin{abstract}
Resumo: Considerando que tradicionalmente compreende-se essência como aquilo que a natureza da coisa é e sem a qual a coisa deixa de ser o que é, levanta-se nesse artigo uma questão que necessita de esclarecimento, a saber, como o pensamento espinosista na Ética pode considerar que a substância única pode ser suporte de infinitos atributos realmente distintos entre si, e que são responsáveis por dar, cada um a sua maneira, a essência dessa substância, sem incorrer numa concepção contraditória de que a substância única, apesar de única, tem infinitas naturezas? Essa questão motiva as discussões levantadas nesse artigo, que tem como objetivo investigar e oferecer uma interpretação acerca da noção de essência a partir da Ética de Espinosa.
\end{abstract}

Palavras-chave: Espinosa; Essência; Monismo.

\begin{abstract}
Considering that essence is traditionally understood as what the nature of the thing is and without which the thing ceases to be what it is, we can think of a question that needs clarification, namely, how Spinoza's thought can consider that the unique substance can be the subject of infinite attributes that are really distinct from each other, and which are responsible for giving, each one in its own way, the essence of that substance without incurring a contradictory conception that the unique substance, although unique, has infinite natures? This question motivates the discussions raised in this article that aims to investigate and offer an interpretation about the notion of essence in Spinoza's Ethics.
\end{abstract}

Keywords: Spinoza; Essence; Monism.

\section{INTRODUÇÃO}

A noção de essência constitui, a princípio, tanto a compreensão de uma instância da realidade, que pré-filosoficamente não é levada em conta, quanto a colocação de um problema conceitual que perpassa a história da metafísica ocidental. Essa duplicidade dá-se justamente porque a noção de essência traz consigo a indicação de que uma investigação da realidade pressupõe o aprofundamento em direção às bases segundo as quais as coisas são como são, isto é, à natureza fun- 
damental do ser das coisas - o que fica claro em função da oposição que há no par essência e aparência -; mas também carrega em si o problema de se saber o que significa explicitamente tal natureza fundamental.

O presente estudo visa a elaborar uma leitura possível justamente do que significa essa natureza fundamental (que geralmente se entende como aquilo que diz o que a coisa é e sem a qual a coisa deixaria de ser o que é) tendo em vista uma compreensão de Espinosa. Para levar a cabo essa tarefa pretende-se, no início, apresentar uma certa visão tradicional baseada na compreensão cartesiana de essência. Em seguida, propõe-se a realização de uma exposição de qual seria o conceito espinosista de essência na Ética, enfocando a oposição entre as noções de "essência como definição/determinação" e "essência como expressão" a fim de elucidar qual delas é mais adequada à visão de Espinosa. Por fim, uma investigação da tese do necessitarismo pretende ser esclarecedora quanto à adesão ou não do presente estudo à tese segundo a qual predicados relacionais fazem parte das essências.

\section{A COMPREENSÃO CARTESIANA DE ESSÊNCIA}

A metafísica de Descartes, assim como a de outros filósofos, admite uma distinção no par essência-existência para todos os seres, com a exceção de Deus, que consiste numa entidade (a única) cuja essência envolve necessariamente a existência: Deus é aquele cuja existência, entre outras coisas, é inseparável da sua natureza própria. No entanto, para Descartes há uma peculiaridade que diz respeito ao conhecimento verdadeiro das essências, que é obtido independentemente de qualquer existente que corresponda a elas. Isso significa que, segundo a metafísica cartesiana, o conhecimento da essência é independente do conhecimento da existência (no caso das coisas materiais, o conhecimento da essência é inclusive anterior ao conhecimento da existência dos corpos), pois basta que se reconheça uma propriedade específica clara e distinta ${ }^{1}$ para que se tenha uma essência real e verdadeira de alguma coisa - mesmo que essa coisa não exista atualmente ou mesmo que nunca se atualize:

[...] é a partir de um atributo, não importa qual, que uma substância é conhecida, mas é uma só, no entanto, a propriedade principal de cada substância, a qual constitui a natureza e a essência da mesma e à qual todas as outras são referidas. A saber, a extensão em comprimento, largura e profundidade constitui a natureza da substância corpórea, e o pensamento constitui a natureza da substância pensante. Pois tudo o mais que pode ser atribuído ao corpo pressupõe a extensão e é apenas um

\footnotetext{
${ }^{1} \mathrm{O}$ pensamento como atributo principal da substância pensante e a extensão como atributo principal da substância corpórea são descobertos respectivamente na Segunda e na Quinta Meditação.
} 
certo modo da coisa extensa; assim como todas as coisas que encontramos na mente são apenas diversos modos de pensar [...] $]^{2}$ (Princípios, art. 53: AT VIII-A, 25).

Com isso em vista, dois pontos do sistema cartesiano devem ser enfatizados tendo como fim a elaboração mais precisa do conceito de essência para Descartes, a saber, 1) a questão do atributo essencial, ou principal, da substância e 2) a questão da essência das coisas materiais.

A questão do atributo essencial da substância é fundamental para a compreensão do pensamento cartesiano, pois é segundo a noção de atributo essencial que Descartes pode justificar o argumento em favor da distinção real entre mente e corpo. Diante da objeção de Arnauld ${ }^{3}$ segundo a qual Descartes não poderia concluir tal distinção, pois não possuiria de fato um conhecimento completo - o que Arnauld compreende como exaustivo - de todas as propriedades da mente e do corpo, Descartes recorre à noção de atributo essencial enquanto aquilo em função do que se pode ter um conhecimento completo da mente. Assim, Descartes não precisa de um conhecimento exaustivo das propriedades da mente e do corpo para saber se são distintos, mas precisa, apenas, do atributo essencial, que é o que define, determina, dá a essência da substância: “[...] verifico aqui que o pensamento é um atributo que me pertence; só ele não pode ser separado de mim [...] pois poderia, talvez, ocorrer que, se eu deixasse de pensar, deixaria ao mesmo tempo de ser ou de existir" (AT VII, 27). Portanto, a descoberta de um atributo essencial na Segunda Meditação, isto é, aquele que não pode ser separado de mim (o pensamento) é a descoberta da essência da mente e, dessa forma, é o conhecimento de que ela prescinde de qualquer propriedade corpórea ${ }^{4}$. Essa leitura é corroborada por Ethel Rocha na passagem que se segue:

E isso se deve ao fato de ter encontrado um atributo essencial que, por ser essencial, é condição suficiente para sua existência. É possível, portanto, concluir que a alma pode existir sem o corpo porque concebo a alma por seu atributo essencial, o pensamento, e nego dela tudo o que pertence à natureza do corpo. (ROCHA, 2006).

Seguindo atentamente os passos envolvidos nessa questão do atributo essencial torna-se claro, juntamente com a tese dos Princípios ${ }^{5}$ (citada anteriormente) que afirma que cada substância possui apenas um único atributo essencial, em que sentido essência é compreendida por Descartes: essência é a definição, a determinação da natureza da coisa, é o que diz o que uma coisa é e sem a qual a coisa deixa de ser o que é. O atributo essencial é aquilo que define, ou determina a substância à medida que ele é a própria substância: o atributo essencial é a natu-

\footnotetext{
${ }^{2}$ As traduções dos Princípios da Filosofia aqui presentes foram retiradas da edição brasileira de 2002.

${ }^{3}$ Cf. AT VII, 197-204.

${ }^{4}$ Cf. AT VII, 219-231.

${ }^{5}$ DESCARTES, 2002, p. 69
} 
reza da substância. Por esse motivo, Descartes esclarece que cada substância possui apenas um atributo essencial, apenas uma natureza, e, nesse sentido, apenas uma definição, pois do contrário cairia numa contradição, já que uma só coisa não pode ter naturezas distintas.

Na esteira dessa noção de essência é importante mostrar como que a questão da essência das coisas materiais vem a reforçá-la. Na Quinta Meditação, Descartes está preocupado com o conhecimento da essência das coisas materiais. Como dito acima, para Descartes o conhecimento verdadeiro das essências independe do conhecimento de existências, bastando apenas o reconhecimento claro e distinto de uma propriedade específica, o que é suficiente para o conhecimento verdadeiro de algo real (porém, não necessariamente existente) ${ }^{6}$. Sendo assim, fica claro logo no início da Quinta Meditação que há uma propriedade clara e distinta que faz parte de todas as ideias de coisas materiais, a saber, a extensão, que é calculável, mensurável matematicamente: "[...] imagino distintamente esta quantidade que os filósofos chamam vulgarmente de quantidade contínua, ou a extensão em longura, largura e profundidade que há nessa quantidade ou, antes, na coisa à qual ela é atribuída"7 (AT VII, 63). Portanto, a essência das coisas materiais é a extensão tridimensional no espaço, calculável de modo preciso, de natureza e relações quantificáveis etc. Corpos, independentemente de sua existência atual, só são corpos se forem extensos.

Considerando que a definição e a natureza do corpo é a extensão, assim como a natureza das diversas operações mentais é o pensamento, há elementos bastantemente fortes para sustentar a compreensão de que o conceito de essência no sistema cartesiano está de fato ligado à noção de determinação do ser da coisa. Embora possa haver outros sentidos da palavra essência na história do pensamento, parece claro que Descartes entende como essência aquilo que define, determina, dá o ser da coisa. Em outras palavras, o conceito cartesiano de essência parece visar apenas àquela dimensão básica e fundamental constitutiva e delimitadora do ser das coisas, a saber, sua natureza. Nesse sentido, em resumo, é razoável defender que Descartes, ao conceber que toda ideia é pensamento e todo corpo é extensão, sustenta, no fim das contas, que o atributo principal das coisas mentais e das coisas corpóreas, porque define a natureza mesma dessas coisas, constitui sua essência.

\footnotetext{
${ }^{6}$ Tudo o que existe corresponde a ou possui uma essência, uma natureza, mas nem toda essência corresponde a ou está atualizada em um existente.

${ }^{7}$ Tradução citada a partir da seguinte edição: DESCARTES, 1973.
} 


\section{DISCUSSÃO SOBRE O CONCEITO DE ESSÊNCIA NA ÉTICA}

A partir da exposição acerca do conceito de essência para Descartes, pretende-se aqui investigar se Espinosa herda uma noção de essência semelhante, isto é, se herda a compreensão de que a essência é a determinação da natureza da coisa, ou se entende essência de modo distinto.

A ontologia de Espinosa, diferentemente da de Descartes, reconhece apenas a existência de uma única substância, que é suporte de infinitos atributos, realmente distintos entre si, a saber, "por Deus entendo o ente absolutamente infinito, isto é, uma substância que consta de infinitos atributos, cada um dos quais exprime uma essência eterna e infinita" (EId6) ; "Deus, ou por outras palavras, a substância que consta de infinitos atributos, cada um dos quais exprime uma essência eterna e infinita, existe necessariamente" (EIp11). Note-se que as referidas citações indicam que os atributos da substância possuem uma relação com a noção de essência. Aparentemente, é possível admitir que a relação entre os conceitos de substância, atributo e essência é contemplada pela visão cartesiana anteriormente comentada de que o atributo é aquele que marca a natureza da substância e, nesse sentido, é responsável por dar a essência dessa substância. Essa compreensão parece ser corroborada pela própria definição de atributo: "por atributo entendo o que o intelecto percebe da substância como constituindo a essência dela" (EId4). Nesse sentido, se os atributos são aqueles que constituem a essência da substância, então podem ser considerados como atributos essenciais e não meros atributos acidentais, o que parece significar que Espinosa afirma, de certo modo, que os atributos são a natureza da substância. Veja-se também que em EIdı é sugerido que a noção de essência envolve a noção de natureza quando o autor afirma que "por causa de si entendo aquilo cuja essência envolve a existência; ou por outras palavras, aquilo cuja natureza não pode ser concebida senão como existente" (grifo meu). Adicionalmente, a definição de essência parece corroborar a interpretação de que a concepção aí envolvida diz respeito à natureza constitutiva que faz das coisas o que elas são:

Digo que pertence à essência de uma coisa aquilo que, sendo dado, faz necessariamente com que a coisa exista e que, sendo suprimido, faz necessariamente com que a coisa não exista; por outras palavras, aquilo sem o qual a coisa não pode nem existir nem ser concebida e, reciprocamente, aquilo que, sem a coisa, não pode nem existir nem ser concebido. (EIId2) $)^{9}$

\footnotetext{
${ }^{8}$ Todas as citações da Ética serão feitas a partir da seguinte tradução e edição: ESPINOSA, 1973.

${ }^{9}$ É importante ressaltar que no original em latim Espinosa não usa o verbo existir nessa passagem, mas usa o termo ponitur para dizer que, uma vez a essência sendo dada, a coisa é posta, o que se entende aqui por colocada, dada, disponibilizada; e o termo tollitur para dizer que, sem a essência, a coisa é retirada, isto é, deixa de estar presente, de estar colocada. Entretanto, compreende-se aqui que essas diferentes traduções apresentam a ideia central de que a essência é aquilo que dá, ou delimita, a natureza da coisa : “Ad essentiam alicuius rei id pertinere
} 
Em síntese, pode-se afirmar que há uma articulação conceitual aparente nos trechos citados que sugere uma compreensão da noção de essência como determinação, delimitação da natureza. Resta, no entanto, investigar com mais precisão a legitimidade dessa articulação tendo em vista alguns pressupostos e implicações teóricas importantes para o pensamento de Espinosa. Nessa direção, propõe-se examinar, nesse momento, o conteúdo do conceito de essência na Ética conjugado, principalmente, a aspectos teóricos da tese da substância única.

De início, afirma-se que o leitor, se embasado pela noção cartesiana de essência, não pode, sem um esforço de interpretação, compreender as teses espinosistas dispostas acima. Isso porque, segundo as teses cartesianas, seria impossível que uma substância possuísse mais de um atributo essencial (o que é o caso, para Espinosa), já que é esse aquilo que determina, no sentido de definir, ou dar, a natureza da substância. E, como visto, para Descartes, uma coisa não pode possuir mais de uma natureza, pois isso seria contraditório, já que, nessas condições, uma coisa seria, ao mesmo tempo, ela e outra, seria uma mesma e uma outra natureza.

Desse modo, deve haver algo de fundamental na filosofia de Espinosa que o permite, sem cair em contradição, dizer que uma única substância possui mais de uma essência. E talvez esse algo seja a compreensão da noção de substância como sendo um sujeito de inerência, isto é, algo que comporta e sustenta uma multiplicidade de maneiras de ser. No entanto, ainda assim, se o atributo é o que se concebe da substância como constituindo a essência dela ${ }^{10}$ e se essência é compreendida como determinação da natureza à medida que é aquilo que põe, coloca, faz com que a coisa exista ${ }^{11}$, isto é, se o atributo essencial define, ou determina, a essência da substância, o problema da contradição na tese espinosista de que a substância possui infinitos atributos permaneceria o mesmo, pois uma única substância seria suporte de infinitas essências, isto é, seria portadora de diversas determinações (distintas e, possivelmente, contraditórias - como é o caso do mental e do extenso) da sua natureza. Considerando isso, Espinosa poderia ter caído em contradição desde o início da exposição da sua ontologia, comprometendo todo o projeto da Ética, o que não se quer admitir aqui sem um exame mais acurado de seu conceito de essência. Isso porque vislumbra-se como hipótese que um aspecto fundamental na ontologia de Espinosa, capaz de permitir com que ele afirme as

\footnotetext{
dico, quo dato res necessário ponitur et quo sublato res necessário tollitur; vel id, sine quo res, et vice versa quod sine re nec esse nec concipi potest." (EIId2).

10 "Por atributo entendo o que o intelecto percebe da substância como constituindo a essência dela" (EId4).

11 "Digo que pertence à essência de uma coisa aquilo que, sendo dado, faz necessariamente com que a coisa exista e que, sendo suprimido, faz necessariamente com que a coisa não exista; por outras palavras, aquilo sem o qual a coisa não pode nem existir nem ser concebida e, reciprocamente, aquilo que, sem a coisa, não pode nem existir nem ser concebido." (EIId2).
} 
teses que afirma, está justamente no conceito de essência, que deve, portanto, ser distinto do conceito cartesiano.

Essa é uma das interpretações avançadas por Alan Donagan em seus artigos Essence and the distinction of attributes in Spinoza's metaphysics (1973) e Substance, essence and attribute in Spinoza, Ethics I (1991). Nesses textos, Donagan defende a tese de que o conceito de essência em Espinosa não corresponde ao de definição ou de constituição da coisa e é justamente por isso que a tese espinosista do monismo não seria contraditória. Dessa forma, a compreensão de que a essência não é definição da coisa permite que se possa conceber uma única substância que possua atributos (aquilo que constitui a essência da substância) realmente distintos entre si.

Segundo Donagan, principalmente no artigo de 1973, o conceito de essência que permite a concepção do monismo espinosista envolve a noção de expressão: a essência, portanto, não define a coisa, mas é meramente uma expressão da natureza da coisa, de forma que uma mesma substância pode ter sua natureza expressa por atributos distintos sem o problema de isso implicar uma contradição. Aqui é importante retomar a proposição 11 da Ética I, anteriormente citada, em que textualmente a noção de essência aparece atrelada à noção de expressão quando Espinosa afirma que cada um dos atributos da substância "[...] exprime uma essência eterna e infinita[...]" (EIpi1). A proposta interpretativa de Donagan parece corroborar a associação entre essência e expressão presente no texto de Espinosa:

Por que não pensar em essência de [...] uma substância como estando numa relação única com cada um de seus atributos: nem uma relação de identidade definicional, nem de causalidade; uma relação que, além disso, pode razoavelmente ser significada ao se falar de cada atributo como "constituindo" ("constituens") ou "expressando" ("exprimens") aquela essência? Uma propriedade formal fundamental dessa relação seria que dois atributos podem, por um lado, ser realmente distintos e, por outro lado, constituírem ou expressarem a mesma essência (DONAGAN, 1973). ${ }^{12}$

No entanto, uma questão se coloca a partir dessa compreensão de essência. Se a essência da substância é expressa distintamente pelos infinitos atributos, qual é de fato a natureza dela? Parece que esse conceito de essência enquanto expressão nos traz um problema quanto à inteligibilidade total do real cara à Espinosa, que concebe que os eventos se relacionam segundo um nexo causal explicável racionalmente. Mais explicitamente, o problema se coloca da seguinte

\footnotetext{
12 "Why not think of the essence of ... a substance as standing in a unique relation to each of its attributes: a relation neither of definitional identity nor of causality; a relation, moreover, which might reasonably be signified by speaking of each attribute as "constituting" ("constituens") or "expressing" ("exprimens") that essence? A fundamental formal property of this relation would be that two attributes might on the one hand be really distinct, and on the other constitute or express the same essence" (DONAGAN, 1973).
} 
forma: como a essência não é definição da natureza da coisa, mas, diferentemente, é apenas expressão de sua natureza; se a substância só é concebida por meio de seus atributos, já que esses são aquilo que o intelecto percebe como constituindo a essência da substância, então só concebemos a substância a partir de expressões de sua natureza, dada pelos atributos. Sendo assim, parece que Espinosa teria de admitir uma espécie de natureza básica da qual os atributos são expressões, que, entretanto, permaneceria oculta, de modo que o princípio da inteligibilidade integral do real não poderia ser aplicado à ontologia espinosista.

Não é a pretensão desse estudo resolver o aparente problema da "natureza oculta" da substância na filosofia espinosista, mas apenas levantar questões acerca do conceito de essência no pensamento de Espinosa. Nesse sentido, a interpretação de Deleuze sobre em que sentido a essência é expressão talvez seja esclarecedora. Num estudo acerca da essência dos modos, em seu livro Spinoza et le problème de l'expression(1968), Deleuze procura entender em que consistem essas essências para tentar dar conta de um problema intrigante da filosofia de Espinosa, que é a passagem do infinito para o finito. Ele amplia a problemática com relação à essência, levando em consideração aspectos importantes para a definição do conceito, a saber, principalmente, a questão do necessitarismo e do imanentismo. Antes de avançar, é importante esclarecer que o necessitarismo diz respeito à compreensão segundo a qual a concepção ontológica da substância única desenvolvida por Espinosa implica que toda a realidade, as coisas e os eventos, tudo aquilo que é, é lógica ou ontologicamente necessário à medida que é uma decorrência necessária da natureza da substância ${ }^{13}$. Já o imanentismo diz respeito à concepção de que fora da substância única nada pode ser dado ou concebido, de modo que tudo aquilo que é tem como base, fundamento, causa e natureza a própria substância ${ }^{14}$. Ainda que não seja o ponto desse artigo, arrisca-se aqui a indicar que necessitarismo e imanentismo são compreensões muito imbricadas no pensamento de Espinosa, de forma que os pontos envolvidos em uma impactam significativamente a outra.

De forma sucinta, segundo Deleuze, a essência não representa a possibilidade de algo que tenda para a existência, nem constitui uma realidade metafísica, ou transcendental, mas é uma realidade física, ou seja, uma espécie de configuração não contraditória dos atributos e que é pensada no intelecto infinito de Deus: "as essências de modos não são nem possibilidades lógicas, nem estruturas mate-

\footnotetext{
${ }^{13}$ Cf.: EIp16, EIp17esc, EIp29 e EIp33.
}

${ }^{14}$ Cf.: EIp14, EIp15, EIp18. 
máticas, nem entidades metafísicas, mas [são] realidades físicas, res physicae" (DELEUZE, 1978, p. 174). ${ }^{15}$.

Admitir que há na essência uma tendência à existência seria admitir uma possibilidade lógica que apontasse para a existência, e assim Espinosa não poderia falar na essência de modos inexistentes, visto que eles, dado o necessitarismo, deveriam ser instanciados. Isso, claramente, mostra-nos uma inconsistência: qualquer enunciação de possibilismo é barrada pelo necessitarismo espinosista. A essência entendida como possibilidade lógica implicaria a instanciação de tudo aquilo para o qual há uma essência. E nesse caso, a distinção entre a essência enquanto mera realidade independentemente de qualquer instanciação e a existência não ocorreria. Entretanto, contra a essência como possibilidade lógica, aparentemente se pode indicar a proposição 24 da primeira parte da Ética: "a essência das coisas produzidas por Deus não envolve a existência".

As essências também não poderiam ser uma realidade transcendental, enquanto entidades metafísicas existentes necessariamente por si, em função do imanentismo, isto é, não há nada na realidade que independa da substância infinita e, nesse sentido, as essências são resultados das próprias disposições internas dessa substância, ou em outras palavras são criadas por Deus: "Deus não é somente causa eficiente da existência das coisas, mas também das essências delas" (EIp25). No entanto, Deus não as cria do nada, assim como o Deus cartesiano cria livremente as verdades eternas sem estar submetido a qualquer lei. Segundo Espinosa, tudo o que é, assim o é a partir da necessidade imanente à própria natureza de Deus, a substância única. Portanto, as essências em nenhum sentido podem ser meras possibilidades, mas representam, segundo Deleuze, realidades físicas não contraditórias e contidas necessariamente nos atributos de Deus, como fica explícito na proposição 8 da segunda parte da Ética: "as ideias das coisas singulares ou modos, que não existem, devem estar compreendidas na ideia infinita de Deus da mesma maneira que estão contidas nos atributos de Deus as essências formais das coisas particulares, ou seja, dos modos".

Deleuze ${ }^{16}$ também discute as diferenças entre as essências dos modos não existentes e dos existentes, a fim de clarificar o conceito de essência. Em linhas gerais, a principal distinção passa pelo problema da individuação. Aparentemente, com base no Breve Tratadode Espinosa ${ }^{17}$, as essências dos modos não existentes não seriam individuadas, pois tal princípio de individuação é dado apenas

\footnotetext{
15 “[...] les essences de modes ne sont ni des possibilités logiques, ni des structures mathématiques, ni des entités métaphysiques, mais des réalités physiques, des res physicae” (DELEUZE, 1968, p. 174).

${ }^{16}$ Cf. DELEUZE, 1968, p.177-178.

${ }^{17}$ Cf. Breve Tratado, edição brasileira de 2012.
} 
pela existência do modo, ou seja, extrinsecamente pela duração, figura e lugar. Entretanto, também com base em outros textos do Breve Tratado, Deleuze termina por admitir que já há alguma individuação intrínseca das essências e, portanto, anterior a qualquer existência; mas que só é completa com a determinação extrínseca da duração, figura e lugar. Que determinação intrínseca seria essa? Segundo Deleuze, são os matizes constitutivos dos modos de ser das coisas:

[...] a brancura [...] tem intensidades variáveis; essas não são adicionadas à brancura como uma coisa a uma outra coisa, como uma figura é adicionada à parede sobre a qual ela é traçada; os graus de intensidade são determinações intrínsecas, modos intrínsecos da brancura que permanece univocamente a mesma sob alguma modalidade que se considere (DELEUZE, 1968, p. 179) ${ }^{18}$.

Assim, torna-se mais claro que a essência consiste na expressão de uma configuração não contraditória dos atributos; configuração essa que representa graus de intensidade dos atributos de Deus como determinações intrínsecas da sua natureza e que é individuada completamente na duração. Portanto, o conceito de essência para Espinosa parece se afastar do conceito cartesiano ao não admitir que a essência seja definitória, mas seja simples expressão de determinações intrínsecas. Sendo assim, o problema visto anteriormente acerca da natureza oculta da substância parece tornar-se impróprio, haja vista a definição de essência como expressiva, e não quididativa. Os atributos expressam configurações intensivas, matizes intrínsecos da natureza de Deus. Por isso os atributos são a expressão do ser da substância única e não expressões de uma natureza oculta e, em última instância, incognoscível. Desse modo, o conceito de essência como expressão indicado no presente artigo a partir de Donagan e especificado com auxílio de Deleuze parece garantir que o princípio de inteligibilidade integral do real não resta ameaçado, além de permitir uma compreensão da tese espinosista da substância única liberada das inconsistências que essa tese poderia portar caso o conceito cartesiano de essência prevalecesse.

\section{A ESSÊNCIA CONTÉM PREDICADOS RELACIONAIS?}

Esta seção pretende investigar uma das principais questões para qualquer filósofo essencialista, a saber, as propriedades essenciais de uma determinada realidade incluem predicados relacionais, tais como "estar à direita de...", "estar num ponto $\mathrm{x}$ do espaço num tempo $\mathrm{y}$ " etc?

\footnotetext{
18 “[...] la blancheur [...] a des intensités variables; celles-ci ne s'ajoutent pas à la blancheur comme une chose à une autre chose, comme une figure s'ajoute à la muraille sur laquelle on la trace; les degrés d'intensité sont des détermination intrinsèques, des modes intrinsèques de la blancheur, qui reste univoquement la même sous quelque modalité qu'on la considère" (DELEUZE, 1968, p. 179)
} 
Como visto acima, aparentemente para Espinosa a essência de um modo finito constitui a expressão de graus de intensidade, isto é, determinações intrínsecas, dos atributos. É possível dizer que a essência de modos inexistentes já possui uma determinação intrínseca, que é um certo grau de intensidade, um matiz, ou mesmo, uma configuração; no entanto, é de modo extrínseco que ela é completamente individuada, isto é, na duração, por meio de uma figura e também de uma determinação espacial. Isso parece indicar que o conceito espinosista de essência não envolve predicados relacionais. Contudo, será compatível com o necessitarismo a admissão de essências, de certo modo, indefinidas (mesmo que não completamente) cuja sucessão da duração é a responsável pela individuação? Isso não pareceria a concordância velada com uma duração infinita contingente, ou seja, com uma duração que determina o modo de ser da natureza contingentemente, causando a ilusão de um necessitarismo, justamente porque é infinita?

Uma análise do necessitarismo de Espinosa torna-se oportuna, então, para que se possa esclarecer em que medida ele admitiria, sem inconsistência, a existência de essências que não possuam predicados relacionais e, de tal modo, sejam diferentes da noção completa da substância individual defendida por Leibniz em seu Discurso de Metafísica (\$8); e, também, de que forma pode-se falar em um necessitarismo em que as essências dos modos finitos não constituem noções completas, mas simples configurações não contraditórias: se é na duração que ocorre a determinação do modo finito, bem como de sua essência ${ }^{19}$, por que não é cabível ao necessitarismo espinosista a categoria de ilusão?

O chamado necessitarismo de Espinosa é desenvolvido principalmente na primeira parte da Ética, na qual a proposição 29 é bastante clara: "na natureza nada existe de contingente; antes, tudo é determinado pela necessidade da natureza divina a existir e a agir de modo certo". A proposição 33 também expõe a visão necessitarista explicitamente: "as coisas não podiam ter sido produzidas por Deus de maneira diversa e noutra ordem do que a que têm". O argumento de Espinosa, descrito na demonstração da proposição 29, processa-se da seguinte forma: nada é contingente porque 1) tudo existe em Deus; 2) Deus existe necessariamente e não contingentemente; e 3) da natureza necessária de Deus provêm necessariamente modos ou modificações; mas 4) Deus não é causa necessária apenas da existência desses modos, pois é causa também de toda e qualquer determinação à ação ou

\footnotetext{
${ }^{19}$ A definição II da segunda parte da Ética parece indicar esta relação entre essência e existência do modo finito que é dada a partir da individuação extrínseca oferecida, basicamente, pela duração: "Digo que pertence à essência de uma coisa aquilo que, sendo dado, faz necessariamente com que a coisa exista e que, sendo suprimido, faz necessariamente com que a coisa não exista; por outras palavras, aquilo sem o qual a coisa não pode nem existir nem ser concebida e, reciprocamente, aquilo que, sem a coisa, não pode nem existir nem ser concebido".
} 
produção que tais modos venham a possuir; e, já que 5) essa determinação não é dada pelos próprios modos a si mesmos, porque qualquer determinação à ação é algo de positivo que deve, portanto, ser fruto da necessidade da natureza de Deus; e que 6) em sendo determinados por Deus é impossível que os modos tornem-se indeterminados; é forçoso concluir que 7) tudo é determinado por Deus e não há nada que seja contingente.

De posse dessa argumentação percebe-se mais facilmente o significado do chamado necessitarismo espinosista. Tudo o que existe, todo o movimento contínuo da duração, todas as relações a que as coisas estão sujeitas são devidas à necessidade da natureza de Deus, estando banida, então, qualquer contingência, de modo que nada poderia ter sido de outra forma, ou seguido outra ordem, como fica claro na proposição 33 da Ética I.

Portanto, retoma-se a questão, o entendimento de que as essências não possuem predicados relacionais, ou até mesmo uma noção completa de tudo o que possa estar envolvido na coisa, é compatível com o necessitarismo?

Aparentemente sim. Entretanto, anteriormente é importante retomar o outro problema acerca do necessitarismo, dada tal compreensão de essência. Aventou-se a hipótese de que nessas condições não haveria um argumento forte para o necessitarismo. Ele poderia apenas consistir na ilusão que a sucessão infinita da duração causaria. Tal sucessão determinaria a existência dos modos e suas relações, porém de forma contingente, seguindo simplesmente esse processo de sucessão infinita em que determinados modos e relações dariam lugar a outros.

Todavia, o pensamento de Espinosa guarda uma peculiaridade interessante que o resguarda dessa hipótese: o imanentismo. Nesse sentido, o referido movimento da duração é o próprio movimento imanente da substância infinita, de modo que tudo o que se segue na sucessão contínua da duração é dado necessariamente, em função de uma necessidade interna da natureza divina, ainda que não haja um "plano prévio" que oriente tal sucessão infinita. É importante ressaltar que o imanentismo é, sem nenhuma dúvida, uma das teses mais importantes da filosofia de Espinosa e constitui uma tese forte, que não pode ser enfraquecida. Não há nenhuma relação de transcendência entre Deus e os modos; os modos são modificações de Deus que são resultado de um desdobramento necessário e não planejado. E parece que a hipótese quanto à contingência presente no movimento da duração (por mais que não fosse percebida como tal) guarda uma relação com a noção de "plano prévio", presente na ideia de um Deus transcendente criador. 
Tendo isso em vista, é cabível dizer que a essência enquanto expressão de graus de intensidade dos atributos, mesmo não incluindo predicados relacionais, é compatível com o necessitarismo justamente em função do imanentismo. Isso significa que não há uma diferença transcendental entre as essências e a existência dos modos finitos (a relação entre a essência de um modo e o modo existente não é a de instanciação), de forma que o surgimento de um modo finito, individuado pela duração, constitui também a determinação de uma essência que antes consistia simplesmente numa configuração não contraditória, um grau de intensidade dos atributos (e agora é enquanto essência singular de um modo finito determinado). As essências, portanto, são frutos necessários da necessidade da natureza divina, assim como os modos: "Deus não é somente causa eficiente da existência das coisas, mas também da essência delas" (EIp25). E, por esse motivo, mesmo sem conter predicados relacionais, não representam nenhuma incompatibilidade com o necessitarismo.

\section{CONCLUSÃO}

Levando em consideração a proposta inicial de oferecer uma leitura do conceito de essência na filosofia de Espinosa, uma análise breve do conceito cartesiano de essência foi empreendida. Segundo o sistema cartesiano, o conceito de essência é quididativo à medida que a essência define, determina, diz qual é a natureza da substância, de forma que dado um atributo essencial é dado, também, uma substância completa e distinta de qualquer outra. Além disto, o tratamento dado por Descartes, na Quinta Meditação, às essências das coisas materiais vem reforçar essa compreensão quididativa de essência, já que basta o reconhecimento de uma propriedade específica clara e distinta para que se tenha uma essência real e verdadeira de alguma coisa (que, no caso, é a propriedade da extensão matematizável). Isso significa que a essência é o lugar das propriedades e das definições que é, a partir disso, instanciada por Deus de acordo com a ordem do todo estabelecida única e exclusivamente segundo seus propósitos.

Diante de uma tal noção de essência, investigou-se se Espinosa a herdaria ou não. Desde o princípio do estudo a interpretação avançada apontou para uma compreensão de essência que não fosse como a cartesiana, dado alguns problemas gerais que essa compreensão constituiria para a filosofia de Espinosa, a saber, principalmente, o problema com relação à inconsistência do monismo. Como não parece razoável pensar que Espinosa tenha se enganado desde o início de seu projeto, ficou claro que a questão estaria assentada numa divergência quanto ao conceito de essência. 
Assim, a leitura proposta nesse estudo convida a pensar a essência como expressão, aquilo que expressa determinadas configurações de intensidade, determinações intrínsecas, dos atributos e cuja individuação e determinação completa é dada juntamente com a existência do modo do qual a essência é uma essência, no processo de desdobramento necessário da natureza de Deus. Isso explicita o caráter não definitório, de determinação da natureza, da essência e também a ausência de predicados relacionais, ou qualquer alusão à ideia leibniziana de noção completa.

A essência, portanto, não é quididativa, não representa uma possibilidade lógica, não constitui uma tendência à existência e nem uma realidade metafísica, segundo Espinosa. A essência, enquanto grau de intensidade, é somente uma realidade resultante da necessidade interna da natureza de Deus e que não possui uma relação de instanciação com os modos existentes dos quais é essência. É em função desse imanentismo que não há nenhuma incompatibilidade de tal conceito de essência com o necessitarismo, mas ao contrário, toda e qualquer configuração não contraditória dos atributos é parte necessária da realidade, o que, por fim, dá às essências o estatuto de virtualidade, ou possibilidade. Mas não o de possibilidade lógica, e sim, o de poder real e necessário de configuração da substância infinita, já que faz parte dos atributos de Deus possuir matizes de intensidade - virtuais -, mesmo que nunca venham a se realizar, pois "as coisas não podiam ter sido produzidas por Deus de maneira diversa e noutra ordem do que a que têm" (EIp23).

\section{REFERÊNCIAS}

DELEUZE, G. Spinoza et le problème del'expression. Les Éditions de Minuit: Paris, 1968. DESCARTES, R. Cottingham, J.; Stoothoff, R.; Murdoch, D. (Ed.). The Philosophical Writings of Descartes. Cambridge: Cambridge University Press, 1984. 3 v.

Meditações Metafísicas. Tr. J. Guinsburg e Bento Prado Júnior. 1. ed. São Paulo: Abril Cultural, 1973. (Coleção Os Pensadores).

Princípios da Filosofia. Tr. Guido Antônio de Almeida (coordenador), Raul Landim Filho, Ethel M. Rocha, Marcos Gleizer e Ulysses Pinheiro. 1. ed. Rio de Janeiro: Editora UFRJ, 2002.

DONAGAN, A. "Essence and the distinction of attributes in Spinoza's metaphysics". In: Spinoza: A Collection of Critical Essays. Marjorie Grene, ed., New York: Doubleday, 1973, p.180.

DONAGAN, A. "Substance, essence and attribute in Spinoza, Ethics I". In: God and Nature: Spinoza's Metaphysics (Ethica I). Yiemiyahu Yovel, ed., E. J. Brill: Leiden - Ney York - Köln, 1991, p. 1-21. 
ESPINOSA. Breve tratado: de Deus, do homem e do seu bem-estar. Tr. Emanuel Angelo da R. Fragoso e Luís César G. Oliva. Belo Horizonte: Autêntica Editora, 2012.

ESPINOSA. B. Ética. Tr. Joaquim de Carvalho (Parte I), Joaquim Ferreira Gomes (Parte II e III), Antônio Simões (Parte IV e V). 1. ed. São Paulo: Abril Cultural, 1973. (Coleção Os Pensadores).

LEIBNIZ. Discurso de metafísica. Tr. Marilena de Souza Chauí Berlinck. 1 ed. São Paulo: Abril Cultural, 1974. (Coleção Os Pensadores).

ROCHA, E. M. "Dualismo, substância e atributo essencial no sistema cartesiano". Analytica, vol. 10, n. 2. Rio de Janeiro: Editora UFRJ, 2006. 